\title{
Thermogravimetric Analysis and Kinetic Calculation on the Combustion Characteristics of Two Typical Shenhua Chars
}

\author{
Baixiang XIANG ${ }^{\mathrm{a}, 1}$, Jun HUANG ${ }^{\mathrm{a}}$, Houzhang $\mathrm{TAN}^{\mathrm{b}}$, Xiaohe XIONG ${ }^{\mathrm{b}}$, Yan $\mathrm{LI}^{\mathrm{a}}$ and \\ Binqiao HAN ${ }^{\mathrm{a}}$ \\ ${ }^{a}$ Guoneng Guohua Electric Power Research Institute Co. Ltd., Beijing 100024, China \\ ${ }^{\mathrm{b}}$ MOE Key Laboratory of Thermo-Fluid Science and Engineering, Xi' an Jiaotong \\ University, Xi'an 710049, China
}

\begin{abstract}
Recently, a new ultra-low nitrogen combustion technology, pyrolysis and gasification coupling combustion, was proposed. The dependence on SCR or SNCR was reduced measurably with this technology. However, given the lower content of volatile matter in semi-chars, the burn-up ratio and combustion efficiency seemed to become lower. Thus, in this study, the combustion characteristics of the Shenhun and Carboniferous char were investigated under combustion conditions with the thermogravimetric method; meantime, kinetic calculation on the combustion characteristics were evaluated with Coats-Redfern method. Experiments indicated that Shenhun char showed good ignition and burnout characteristics when the pyrolysis temperature ranged from $973.15 \mathrm{~K}$ to $1073.15 \mathrm{~K}$; meanwhile, Carboniferous char showed good ignition and burnout characteristics when the pyrolysis temperature ranged from $873.15 \mathrm{~K}$ to $973.15 \mathrm{~K}$. Besides, both the calculations and experiments indicated that Shenhun char showed better combustion characteristics than Carboniferous char.
\end{abstract}

Keywords. Thermogravimetric analysis, kinetic calculation, combustion characteristics, semi-chars

\section{Introduction}

With the increasingly serious environmental problems and deepening understanding of sustainable development, the domestic environmental regulatory policies have been developed rapidly in China [1]. In order to meet the increasingly stringent environmental requirements, high-efficient flue gas denitrification technologies (e.g., SNCR, SCR) have been widely used in recent years. However, with the NOx emission decreasing, the ammonia slip increased [2]. Various damages, including catalyst deactivation, fouling, corrosion, insufficient output at high load, could be caused [3-5]. The ammonia slip has become the urgent problem for coal-fired power plants. To reduce the dependence on SCR and SNCR, a new ultra-low nitrogen combustion

${ }^{1}$ Corresponding Author, Baixiang XIANG, Guoneng Guohua Electric Power Research Institute Co. Ltd., Beijing 100024, China; Email: 20035058@chnenergy.com.cn. 
technology, pyrolysis and gasification coupling combustion, was proposed [6-7]. In this technology, a certain percentage of pulverized coal was heated to the appropriate temperature in a precombustion chamber under considerably lower than the stoichiometric ratio. Consequently, a large amount of volatile matter, including the reductive components (e.g., $\mathrm{CH}_{4}, \mathrm{H}_{2}, \mathrm{CO}$, etc.) and nitrogen-containing precursors (e. g., $\mathrm{NH}_{3}, \mathrm{HCN}$, etc.), was released under such a condition. Then, the high temperature semi-chars were carried to the primary combustion zone by pneumatic conveying after separated, and burned with air staging combustion [8-10]. Given the lower content of volatile matter in semi-chars, the burn-up ratio and combustion efficiency were likely to be affected. However, the combustion characteristics of semi-chars under ultro-low nitrogen combustion are still seldom reported in previous researches to date.

To better understand pyrolysis and gasification coupling combustion technology, the thermal characteristics of Shenhun and Carboniferous char under combustion conditions were evaluated by the non-isothermal thermogravimetric method (TGA) and kinetic calculation respectively in this work, providing a theory foundation for the application of the pyrolysis and gasification coupling combustion technology in the semi-char combustion field.

\section{Experimental Bench}

\subsection{Experimental}

With thermal analysis as a reference, the combustion characteristics of Shenhun and Carboniferous chars shown in table 1 were studied in air combustion atmosphere using a Netzsch STA449F5 analyser with Non-isothermal TG/DTG module in this work. To minimize mass transfer limitations and heat transfer effects, a small amount of sample (e.g., $5 \mathrm{mg}$ ) and a moderate heating rate $(40 \mathrm{~K} / \mathrm{min})$ were used in the experiments. Table 2 provided the ultimate and proximate analysis of Shenhun and Carboniferous chars.

Table 1. Shenhun and Carboniferous char making conditions.

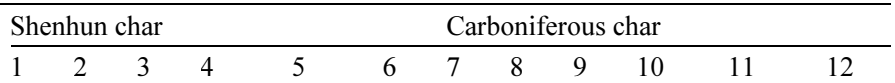

Particle size distribution $(\mu \mathrm{m})$ 75-9738-6175-97106-125150-20075-9775-9738-6175-97106-125150-200 75-97

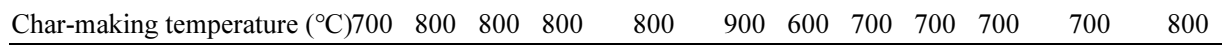

Table 2. The ultimate and proximate analysis of Shenhun and Carboniferous chars.

\begin{tabular}{llllllllll}
\hline & \multicolumn{3}{c}{ Proximate analysis (wt.\%) } & \multicolumn{7}{c}{ Ultimate analysis (wt.\%) } \\
\cline { 2 - 10 } & $\mathrm{V}_{\mathrm{ar}}$ & $\mathrm{A}_{\mathrm{ar}}$ & $\mathrm{M}_{\mathrm{ar}}$ & $\mathrm{FC}_{\mathrm{ar}}$ & $\mathrm{C}_{\mathrm{ar}}$ & $\mathrm{H}_{\mathrm{ar}}$ & $\mathrm{O}_{\mathrm{ar}}$ & $\mathrm{N}_{\mathrm{ar}}$ & $\mathrm{S}_{\mathrm{ar}}$ \\
\hline Shenhun char & 6.36 & 29.31 & 0.91 & 65.35 & 62.29 & 1.54 & 5.35 & 0.94 & 0.57 \\
Carboniferous char & 7.29 & 39.49 & 0.71 & 55.44 & 51.85 & 1.73 & 5.47 & 1.11 & 0.35 \\
\hline
\end{tabular}

\subsection{Experimental Results}

To date, a series of methods for determining the burnout temperature $\left(T_{\mathrm{b}}\right)$ and ignition temperature $\left(T_{\mathrm{i}}\right)$ have been reported in previous researches [11-16]. The method in reference to TG and DTG profiles is one of the most popular and reliable determination 
methods $[11,14,16]$. Thus, as shown in figure 1 , the burnout and ignition temperatures could be defined as following $[11,14,16]$ : firstly, a vertical line, through the DTG peak (point A), was made upwards to meet the TG curve (point B); secondly, through the point $\mathrm{B}$, a tangent line to TG curve was made and met the extended TG initial level line (point $\mathrm{C}$ ); thirdly, through the point $\mathrm{C}$, the other vertical line was made downwards to meet the temperature coordinate axis (point D). Subsequently, the temperature of point $\mathrm{D}$ could be defined as the ignition temperature, and the burnout temperature could be defined as the corresponding temperature of point $\mathrm{E}$, which was the boundary point between the maximum mass loss-rate peak and the decomposition peak of minerals. Thus, with reference to the aforementioned methods, the ignition temperatures and burnout temperatures of the pulverized semi-char samples listed in table 1 were determined in reference to the TG and DTG profiles shown in figures 2-5.

Figures 2-3 indicated the ignition temperatures of Shenhun char were lower than those of Carboniferous char at $1073.15 \mathrm{~K}$, moreover, a significantly lower trend was observed at $973.15 \mathrm{~K}$ (referred to pyrolysis temperature, same to below) when the particle size ranged from $75 \mu \mathrm{m}$ to $97 \mu \mathrm{m}$. The burnout temperatures of Shenhun char were dramatically lower than those of Carboniferous char at $1073.15 \mathrm{~K}$, however, a briefly higher trend was observed at $973.15 \mathrm{~K}$ when the particle size ranged from 75 $\mu \mathrm{m}$ to $97 \mu \mathrm{m}$, as shown in figures $4-5$.

Temperature $\left({ }^{\circ} \mathrm{C}\right)$

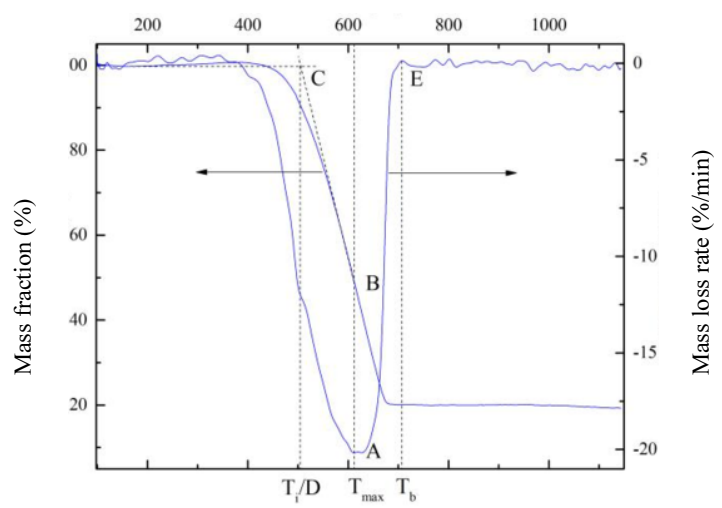

Figure 1. The combustion characteristic temperatures definition sketch.

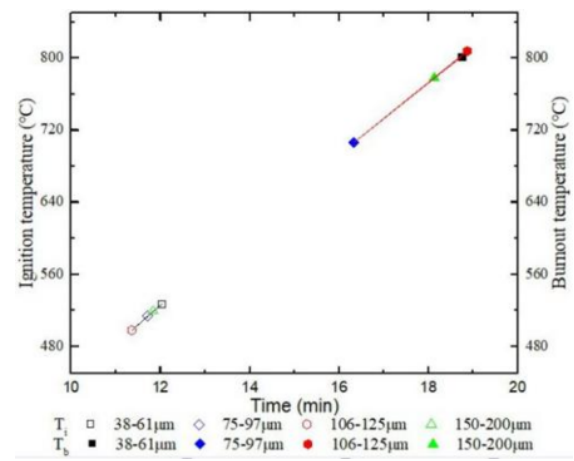

Figure 2. The burnout and ignition temperatures of Shenhun chars at $1073.15 \mathrm{~K}$.

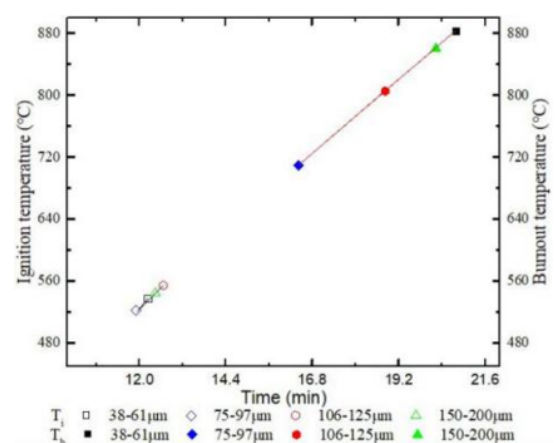

Figure 3. The ignition and burnout temperatures of Carboniferous chars at $973.15 \mathrm{~K}$. 


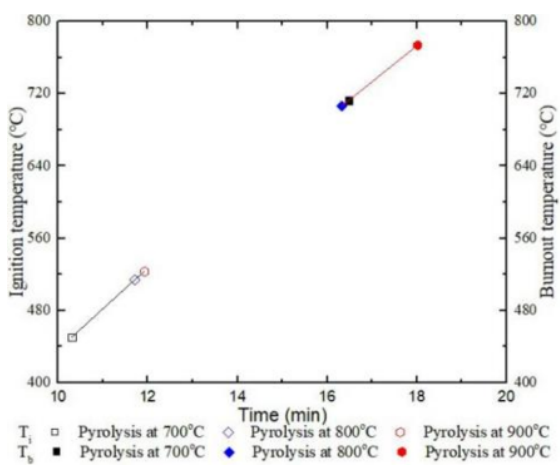

Figure 4. The ignition and burnout temperatures of Shenhun chars when the particle diameter ranged from $75 \mu \mathrm{m}$ to $97 \mu \mathrm{m}$.

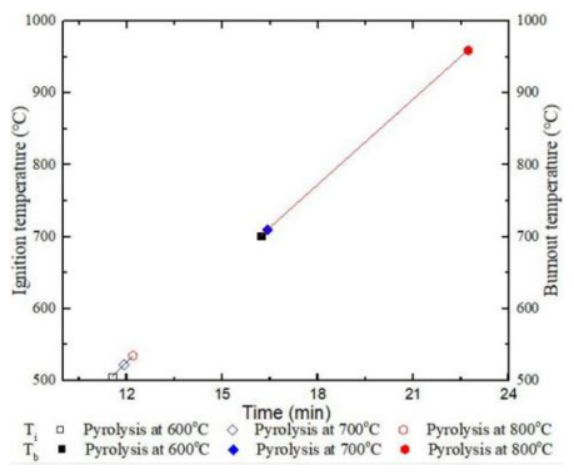

Figure 5. The ignition and burnout temperatures of Carboniferous chars when the particle diameter ranged from $75 \mu \mathrm{m}$ to $97 \mu \mathrm{m}$.

\section{Kinetic Calculation}

\subsection{Approach}

The Arrhenius equation is one of the most common methods used to evaluate the kinetics during pyrolysis of coal, coke and semi-char [14-23]. Then, with Arrhenius equation as reference, the kinetic parameters of Shenhun and Carboniferous chars shown in table 1 were studied. The kinetic equation of heterogeneous solid-state thermal transformation studied by TG could be described with the following formula [14-23].

$$
\frac{\mathrm{d} \alpha}{\mathrm{d} t}=\mathrm{f}(\alpha) \mathrm{k}(T)
$$

where $t$ is the time, min, $T$ is the temperature, $\mathrm{K}$, and $\alpha$, the degree of combustion, $\%$, can be determined as the following formula

$$
\alpha=\frac{m_{\mathrm{o}}-m}{m_{\mathrm{o}}-m_{\mathrm{f}}}
$$

where $m_{\mathrm{o}}$ and $m_{\mathrm{f}}$ are the mass of the sample at the beginning and at the end of the mass loss reaction respectively, $\mathrm{mg}$, and $m$ is the mass of the sample at time $t$ or temperature $T$, mg. $\mathrm{f}(\alpha)$, the reaction model, is the functional relation between the rate and degree of combustion. $\mathrm{k}(T)$, the rate constant, can be formulated using Arrhenius equation:

$$
\mathrm{k}(T)=A \exp \left(-\frac{E}{R T}\right)
$$

where $A$ is the pre-exponential factor, $\min ^{-1}, E$ is the activation energy, $\mathrm{kJ} / \mathrm{mol}$, and $R$ is the ideal gas constant, $\mathrm{J} /(\mathrm{mol} \cdot \mathrm{K})$. As the heating rate is constant, the following equation can be obtained under such a condition: 


$$
\beta=\frac{\mathrm{d} T}{\mathrm{~d} t}
$$

where $\beta$ is the heating rate, $\mathrm{K} / \mathrm{min}$. Submitting equations (3)-(4) to equation (1) and separating the variables, thus equation (1) can be integrated as

$$
\frac{\mathrm{d} \alpha}{\mathrm{f}(\alpha)}=\frac{1}{\beta} A \exp \left(-\frac{E}{R T}\right) \mathrm{d} T
$$

Due to the negligible reaction rate at the starting temperature, the starting temperature can be set as $T=0 \mathrm{~K}$ [20]. The variables can then be separated and equation (5) can be integrated as

$$
\int_{0}^{\alpha} \frac{\mathrm{d} \alpha}{\mathrm{f}(\alpha)}=\frac{1}{\beta} A \int_{0}^{T} \exp \left(-\frac{E}{R T}\right) \mathrm{d} T
$$

To date, a series of model-fitting methods for evaluating kinetic parameters have been reported in previous studies [20]. Compared to other model-fitting methods considering single thermoanalytical curve for investigating kinetic triplet (i. e., $\mathrm{f}(\alpha), A$ and $E$ ), the Coats-Redfern method was more desirable [14]. Thus, with reference to Coats-Redfern method, the reaction mechanism function can be formulated as the following equation:

$$
\mathrm{f}(\alpha)=(1-\alpha)^{n}
$$

where $n$ is the reaction order. However, it can be considered as a first order reaction for coal combustion reported in previous research results [19-20]. Thus, by submitting equation (7) into equation (6), there is

$$
\int_{0}^{\alpha} \frac{\mathrm{d} \alpha}{(1-\alpha)}=\frac{1}{\beta} A \int_{0}^{T} \exp \left(-\frac{E}{R T}\right) \mathrm{d} T
$$

Rearranging and integrating equation (8), there is

$$
\ln \left[\frac{-\ln (1-\alpha)}{T^{2}}\right]=\ln \left[\frac{A R}{\beta E}\left(1-\frac{2 R T}{E}\right)\right]-\frac{E}{R T}
$$

In reference to most values of $E$ investigated previously, the $R T / E<<1$ in equation (9) and then the $(1-2 R T / E) \approx 1$ under approximative assumptions [20]. Then, the integrated kinetic equation could be formulated as

$$
\ln \left[\frac{-\ln (1-\alpha)}{T^{2}}\right]=\ln \frac{A R}{\beta E}-\frac{E}{R T}
$$

Consequently, the plots of $\ln \left[-\ln (1-\alpha) / T^{2}\right]$ versus $1 / T$ acquired from the experiments could be a line at certain temperatures, and $E$ can be obtained from the slope (i.e., $-E / R$ ), whereas $A$ can be acquired from the intercept [20]. 


\subsection{Results and Discussion}

Figures 6-9 provided the plots of $\ln \left[-\ln (1-\alpha) / T^{2}\right]$ versus $1 / T$ of Shenhun and Carboniferous chars listed in table 1 when the pyrolysis temperature ranged from 973.15 K to $1173.15 \mathrm{~K}$ and from $873.15 \mathrm{~K}$ to $1073.15 \mathrm{~K}$, respectively. As shown in figures 6-9, the combustion process can be described by three consecutive first order reactions corresponding to three consecutive temperature ranges, and the good correlation coefficients indicated that the calculations obtained by the corresponding first-order reaction models agreed well with the experiments. Consequently, the conversion $\alpha$ of each stage can be formulated separately. By applying Equation 10 to each of the aforementioned stages separately, the values of $E$ and $A$ under different stages can be obtained from the slope and intercept, respectively. Table 3 showed the kinetic parameters of the pulverized semi-char samples listed in table 1 . E values of Shenhun char are dramatically lower than those of Carboniferous char when the particle size ranged from $75 \mu \mathrm{m}$ to $97 \mu \mathrm{m}$ at $973.15 \mathrm{~K}$; meantime, $A$ values of Shenhun char were dramatically higher than those of Carboniferous char when the particle size ranged from $75 \mu \mathrm{m}$ to $97 \mu \mathrm{m}$ at $973.15 \mathrm{~K}$, as shown in table 3 . With the activation increasing, the ignition temperature decreased; in the meantime, the combustion showed more vigorously with the pre-exponential factor increasing. Thus, it can be concluded that Shenhun char is more easily ignitable than Shenhun char with the aforementioned particle size distributions and at aforementioned pyrolysis temperatures, which is consistent with the experiments in this work well.

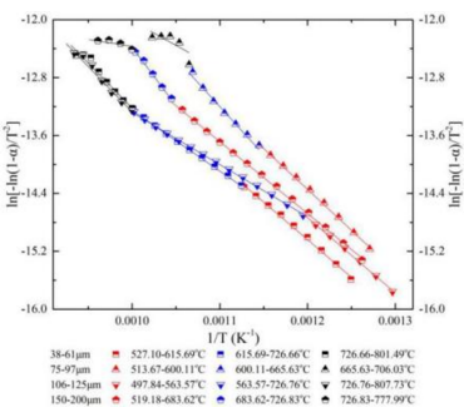

Figure 6. The plots of $\ln \left(-\ln (1-\alpha) / T^{2}\right)$ vs $1 / T$ of Figure 7. The plots of $\ln \left(-\ln (1-\alpha) / T^{2}\right)$ vs $1 / T$ of Shenhun chars at $1073.15 \mathrm{~K}$.

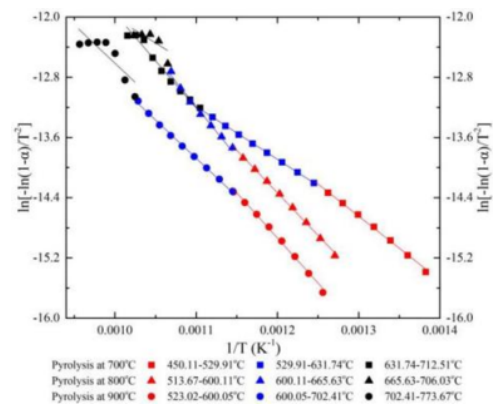

Figure 8. The plots of $\ln \left(-\ln (1-\alpha) / T^{2}\right)$ vs $1 / T$ of Figure 9. The plots of $\ln \left(-\ln (1-\alpha) / T^{2}\right)$ vs $1 / T$ of Shenhun chars when the particle diameter ranged Carboniferous chars when the particle diameter ranged from $75 \mu \mathrm{m}$ to $97 \mu \mathrm{m}$.

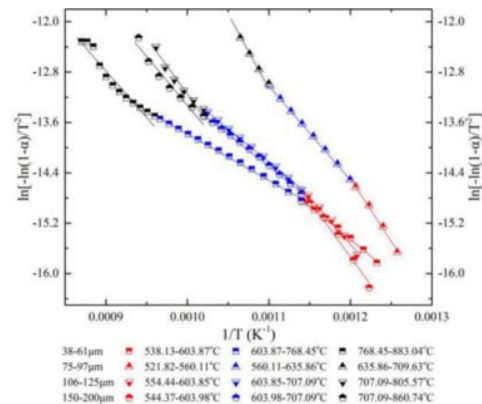

Carboniferous chars at $973.15 \mathrm{~K}$.

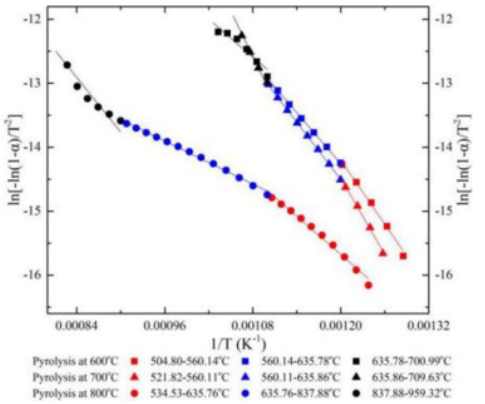

from $75 \mu \mathrm{m}$ to $97 \mu \mathrm{m}$. 
Table 3. The kinetic parameters of Shenhun and Carboniferous chars.

\begin{tabular}{|c|c|c|c|c|c|}
\hline Items & Temperature $\left({ }^{\circ} \mathrm{C}\right)$ & Conversion range $(\%)$ & $E\left(\mathrm{~kJ} \cdot \mathrm{mol}^{-1}\right)$ & $A\left(\min ^{-1}\right)$ & $R^{2}$ \\
\hline \multirow{3}{*}{ No.1 } & $450.11-529.91$ & $10.3017-35.3414$ & 104.3460 & $9.1098 \times 10^{5}$ & 0.9788 \\
\hline & $529.91-631.74$ & $35.3414-77.7387$ & 58.2461 & $1.1629 \times 10^{3}$ & 0.9997 \\
\hline & $631.74-712.51$ & $77.7387-99.0515$ & 70.7869 & $9.5202 \times 10^{3}$ & 0.9982 \\
\hline \multirow{3}{*}{ No.2 } & $527.10-615.69$ & $10.3123-38.8249$ & 86.1349 & $3.0851 \times 10^{4}$ & 0.9973 \\
\hline & $615.69-726.66$ & $38.8249-83.5502$ & 69.7362 & $2.6089 \times 10^{3}$ & 0.9997 \\
\hline & $726.66-801.49$ & $83.5502-98.5741$ & 103.7733 & $2.3987 \times 10^{5}$ & 0.9489 \\
\hline \multirow{3}{*}{ No.3 } & $513.67-600.11$ & $14.7618-56.0451$ & 93.8351 & $2.0447 \times 10^{5}$ & 0.9986 \\
\hline & $600.11-665.63$ & $56.0451-94.4380$ & 110.6528 & $2.2646 \times 10^{6}$ & 0.9895 \\
\hline & $665.63-706.03$ & $94.4380-98.9760$ & 55.8390 & $1.3474 \times 10^{3}$ & 0.6043 \\
\hline \multirow{3}{*}{ No.4 } & $497.84-563.57$ & $8.1852-25.0142$ & 86.3808 & $4.3435 \times 10^{4}$ & 0.9976 \\
\hline & $563.57-726.76$ & $25.0142-82.7692$ & 59.9471 & $6.7178 \times 10^{2}$ & 0.9996 \\
\hline & $726.76-807.73$ & $82.7692-98.8430$ & 104.5229 & $2.5115 \times 10^{5}$ & 0.9652 \\
\hline \multirow{3}{*}{ No.5 } & $519.18-683.62$ & $13.0054-84.8553$ & 82.5880 & $2.5429 \times 10^{4}$ & 0.9994 \\
\hline & $683.62-726.83$ & 84.8553-98.2914 & 134.8181 & $3.0349 \times 10^{7}$ & 0.9957 \\
\hline & 726.83-777.99 & $98.2914-99.2850$ & 15.6941 & $2.1337 \times 10^{0}$ & 0.5718 \\
\hline \multirow{3}{*}{ No.6 } & $523.02-600.05$ & $9.5457-36.9364$ & 99.6356 & $2.7541 \times 10^{5}$ & 0.9968 \\
\hline & $600.05-702.41$ & $36.9364-86.7268$ & 84.3955 & $3.4542 \times 10^{4}$ & 0.7176 \\
\hline & $702.41-773.67$ & $86.7268-99.0466$ & 84.3718 & $2.6903 \times 10^{4}$ & 0.9982 \\
\hline \multirow{3}{*}{ No.7 } & $504.80-560.14$ & $8.7729-36.2214$ & 138.6503 & $2.2301 \times 10^{8}$ & 0.9960 \\
\hline & $560.14-635.78$ & $36.2214-87.3228$ & 110.5412 & $2.9069 \times 10^{6}$ & 0.9994 \\
\hline & $635.78-700.99$ & $87.3228-99.1681$ & 81.8643 & $5.5716 \times 10^{4}$ & 0.9201 \\
\hline \multirow{3}{*}{ No.8 } & $538.13-603.87$ & $8.4017-23.9875$ & 88.1347 & $2.7668 \times 10^{4}$ & 0.9964 \\
\hline & $603.87-768.45$ & $23.9875-77.3824$ & 61.0068 & $4.6936 \times 10^{2}$ & 0.9987 \\
\hline & $768.45-883.04$ & $77.3824-99.7530$ & 123.0347 & $1.0240 \times 10^{6}$ & 0.9524 \\
\hline \multirow{3}{*}{ No.9 } & $521.82-560.11$ & $9.4971-29.1687$ & 165.2329 & $9.3108 \times 10^{9}$ & 0.9972 \\
\hline & $560.11-635.86$ & $29.1687-84.8406$ & 124.0862 & $1.8014 \times 10^{7}$ & 0.9998 \\
\hline & $635.86-709.63$ & 84.8406-100 & 196.7242 & $4.0958 \times 10^{11}$ & 0.9712 \\
\hline \multirow{3}{*}{ No. 10} & $554.44-603.85$ & $9.8861-27.9131$ & 125.0958 & $7.5609 \times 10^{6}$ & 0.9928 \\
\hline & $603.85-707.09$ & $27.9131-77.1765$ & 87.9117 & $3.1731 \times 10^{4}$ & 0.9996 \\
\hline & $707.09-805.57$ & $77.1765-100$ & 147.4782 & $7.0759 \times 10^{7}$ & 0.9267 \\
\hline \multirow{3}{*}{ No.11 } & $544.37-603.98$ & $5.8349-26.3972$ & 147.2077 & $1.7748 \times 10^{8}$ & 0.9900 \\
\hline & $603.98-707.09$ & $26.3972-73.2483$ & 84.8089 & $1.8954 \times 10^{4}$ & 0.9980 \\
\hline & $707.09-860.74$ & $73.2483-100$ & 128.8702 & $5.5038 \times 10^{6}$ & 0.9426 \\
\hline \multirow{3}{*}{ No.12 } & $534.53-635.76$ & $6.0783-27.8146$ & 83.0257 & $9.9337 \times 10^{3}$ & 0.9900 \\
\hline & $635.76-837.88$ & $27.8146-78.8284$ & 46.7304 & $4.5391 \times 10^{1}$ & 0.9967 \\
\hline & 837.88-959.32 & $78.8284-99.9933$ & 118.3249 & $2.1896 \times 10^{5}$ & 0.8383 \\
\hline
\end{tabular}

\section{Conclusions}

In this study, the ignition and burnout characteristics of Shenhun and Carboniferous char under combustion conditions were evaluated with the non-isothermal thermogravimetric method and kinetic calculation respectively. Furthermore, kinetic calculation on the combustion characteristics were evaluated with Coats-Redfern method. Experiments indicated that Shenhun char showed good ignition and burnout characteristics when pyrolysis temperature ranged from $973.15 \mathrm{~K}$ to1073.15 K; however, Carboniferous char presented good ignition and burnout characteristics when 
pyrolysis temperature ranged from $873.15 \mathrm{~K}$ to $973.15 \mathrm{~K}$. Both the calculations and experiments indicated that Shenhun char showed better combustion characteristics than Carboniferous char. In addition, the burnout characteristics became worse with the increase of particle size. Thus, to provide a theory foundation for the application of the pyrolysis and gasification coupling combustion technology in the semi-char combustion field, the particle size below $125 \mu \mathrm{m}$ and pyrolysis temperature ranged from $873.15 \mathrm{~K}$ to $1073.15 \mathrm{~K}$ were recommended.

\section{Acknowledgements}

The financial support provided by the National Key R\&D Program of China (No. 2018YFB0604203) is gratefully acknowledged.

\section{References}

[1] 2011 Emission Standard of Air Pollutants for Thermal Power Plants (Beijing: Ministry of Environmental Protection) GB13223-2011. (in Chinese)

[2] You S L, Luo H H, Wang Z, Yao Y Q, Liu X R, Sun Y Q and Chen F 2019 Study on ammonia escape rate control technology of SCR denitrification system in coal-fired power plant Huodian Technology 41 (2) 55-59. (in Chinese)

[3] Li J J, Yang H R and Wu Y X 2013 Effects of the updated National Emission Regulation in China on circulating fluidized bed boilers and the solutions to meet them Environmental Science \& Technology 47 6681-6687.

[4] Muzio L J, Quartucy G C and Cichanowiczy J E 2002 Overview and status of post-combustion NOx control: SNCR, SCR and hybrid technologies International Journal of Environment and Pollution 17 (1/2) 4-30.

[5] Zhou T, Liu S G and Wu J M 2008 Technologies of NOx emission control for coal-fired power plants Environmental Engineering 26 (6) 82-85. (in Chinese)

[6] Ouyang Z, Wen L, Man C, Zhu J and Liu J 2018 Experimental study on combustion, flame and NOx emission of pulverized coal preheated by a preheating burner Fuel Processing Technology 179 197-202.

[7] Ouyang Z, Lu Q and Zhu J 2013 An experimental study on NOx emissions in combustion of pulverized coal preheated in a circulating fluidized bed Energy \& Fuels 27(12) 7724-7729.

[8] Man C, Zhu J, Ouyang Z, Liu J and Lyu Q 2018 Experimental study on combustion characteristics of pulverized coal preheated in a circulating fluidized bed Fuel Processing Technology 172 72-78.

[9] Ouyang Z Q, Zhu J G and Lu Q G 2013 Experimental study on preheating and combustion characteristics of pulverized anthracite coal Fuel 113 122-127.

[10] Ouyang Z Q, Zhu J G and Lu Q G 2014 Experimental study on combustion and NOx emission of pulverized anthracite coal preheated by a circulating fluidized bed Proceedings of the CSEE 34(11) 1478-1754. (in Chinese)

[11] He X F, Wu H J, Yang L Wei J G and Zhou A N 2017 Combustion characteristics of bio-briquette pyrolysis semi-char Chemical Engineering (China) 45 (2) 61-67. (in Chinese)

[12] Gil M V, Riaza J, Álvarez L, Pevida C, Pis J J and Rubiera F 2012 A study of oxy-coal combustion with steam addition and biomass blending by thermogravimetric analysis Journal of Thermal Analysis and Calorimetry 109 (1) 49-55.

[13] Xian X H, Du Y G and Zhang G G 2011 Combustion characeristics of coal blending by TG-DTG/DTA Coal Conversion 34 (3) 67-70. (in Chinese)

[14] Li X G, Ma B G, Xu L, Hu Z W and Wang X G 2006 Thermogravimetric analysis of the cocombustion of the blends with high ash coal and waste tyres Thermochimica Acta 441 (1) 79-83.

[15] Gu L F, Chen X P, Zhao C S 2003 Study on co-combustion of the blends with municipal sludge and coal by thermogravimetric analysis Journal of Engineering for Thermal Energy and Power 18 (6) 561563. (in Chinese)

[16] Nie Q H, Sun S Z and Li Z Q 2001 Thermogravimetric Analysis on the Combustion Characteristics of Brown Coal Blends Journal of Combustion Science and Technology 7 (1) 72-76. (in Chinese) 
[17] Kök M V, Pokol G, Keskin C, Madarász J and Bagci S 2004 Combustion characteristics of lignite and oil shale samples by thermal analysis techniques Journal of Thermal Analysis and Calorimetry 76 (1) 247-254

[18] Gil M V, Casal D, Pevida C, Pis J J and Rubiera F 2010 Thermal behaviour and kinetics of coal/biomass blends during co-combustion Bioresource Technology 101 (14) 5601-5608.

[19] Cai J, Wang Y, Zhou L and Huang Q 2008 Thermogravimetric analysis and kinetics of coal/plastic blends during co-pyrolysis in nitrogen atmosphere Fuel Processing Technology 89 (1) 21-27.

[20] Niu S L, Lu C M and Han K H 2009 Thermogravimetric analysis of combustion characteristics and kinetic parameters of pulverized coals in oxy-fuel atmosphere Journal of Thermal Analysis and Calorimetry 98 (1) 267-274.

[21] Wu H X, Li H B, and Zhao Z L 2009 Thermogravimetric analysis and pyrolytic kinetic study on coal/biomass blends Journal of Fuel Chemistry and Technology 37 (5) 538-545. (in Chinese)

[22] López-Fonseca R, Landa I, Gutiérrez-Ortiz M A and González-Velasco J R 2005 Non-isothermal analysis of the kinetics of the combustion of carbonaceous materials Journal of Thermal Analysis and Calorimetry 80 (1) 65-69.

[23] Otero M, Gómez X, Morán A I and Morán A 2008 Non-isothermal thermogravimetric analysis of the combustion of two different carbonaceous materials: coal and sewage sludge Journal of Thermal Analysis and Calorimetry 93 (2) 619-626. 